\title{
DESAFIOS DA FORMAÇÃO DE PROFESSORES ALFABETIZADORES: EM BUSCA DA APROPRIAÇÃO DA LINGUAGEM ESCRITA COMO DESENVOLVIMENTO HUMANO
}

\author{
RETOS DE LA FORMACIÓN DE PROFESORES ALFABETIZADORES: \\ EN BÚSQUEDA DE LA APROPIACIÓN DEL LENGUAJE ESCRITO COMO \\ DESARROLLO HUMANO
}

\section{CHALLENGES OF THE EDUCATION OF LITERACY TEACHERS: IN SEARCH OF THE APPROPRIATION OF WRITTEN LANGUAGE AS HUMAN DEVELOPMENT}

Sônia Cláudia Barroso da ROCHA ${ }^{1}$ Michelle de Freitas BISSOLI ${ }^{2}$

RESUMO: Neste artigo, buscamos refletir sobre os desafios presentes na formação de professores responsáveis pela alfabetização das crianças, a partir da compreensão da linguagem escrita como instrumento cultural complexo, cuja apropriação resulta no desenvolvimento das funções psicológicas superiores. A partir de uma perspectiva histórico-cultural do desenvolvimento humano, percebemos quão grandes são esses desafios, considerando o caráter fragmentado da formação dos professores, que tendem a tomar retórica por teoria e ativismo por prática, desvinculando os dois âmbitos da produção do conhecimento humano. Trata-se de uma formação que pouco tem contemplado os conteúdos a serem ensinados às crianças, priorizando as capacidades mínimas que sirvam à vida cotidiana em detrimento das capacidades máximas alcançadas pelo gênero humano. Sendo a linguagem escrita e seu ensino objetos complexos, específicos, não-cotidianos e conceituais, não se pode conhecê-los verdadeiramente se não for pela via do pensamento conceitual que também precisa ser ensinado. Com isso, embora pareça longe a superação do quadro de analfabetismo funcional no país, consideramos que a mediação das abstrações, na formação docente, constitui caminho essencial à luta pelo direito de todas as pessoas ao desenvolvimento das capacidades de leitura e escrita.

PALAVRAS-CHAVE: Formação de professores. Apropriação da linguagem escrita. Desenvolvimento humano.

RESUMEN: En este artículo, buscamos reflexionar sobre los retos presentes en la formación de profesores responsables por la alfabetización de los niños, a partir de la comprensión del lenguaje escrito como instrumento cultural complejo cuya apropiación resulta en el desarrollo de las funciones sicológicas superiores. A partir de una perspectiva histórico-cultural del desarrollo humano, percibimos como son grandes esos desafios, considerando el carácter fragmentado de la formación de los profesores, que tienden a concebir retórica por teoría y activismo por práctica, desvinculando los dos ámbitos de la producción del conocimiento humano. Se trata de una formación que poco ha contemplado los contenidos que se deben enseñar a los niños, priorizando las

${ }^{1}$ Doutoranda em Educação. Faculdade de Educação, UFAM. Programa de Pós-graduação em Educação, Manaus, Brasil. E-mail: sonyaclaudya@yahoo.com.br.

${ }^{2}$ Doutora em Educação. Faculdade de Filosofia e Ciềncia - FFC/UNESP, Marília, Brasil. Professora da Universidade Federal do Amazonas, Manaus, Brasil. E-mail: mibissoli@yahoo.com.br. 
capacidades mínimas que sirvan a la vida cotidiana en detrimento de las capacidades máximas alcanzadas por el género humano. Siendo el lenguaje escrito y su enseñanza objetos complejos, específicos, no-cotidianos y conceptuales, no se puede conocerlos verdaderamente si no es por la vía del pensamiento conceptual que también necesita ser enseñado. Con eso, aunque parezca lejana la superación del cuadro de analfabetismo funcional en el país, consideramos que la mediación de las abstracciones, en la formación docente, constituye camino esencial a la lucha por el derecho de todas las personas al desarrollo de las capacidades de lectura y escritura.

PALABRAS CLAVE: Formación de profesores. Apropiación del lenguaje escrito. Desarrollo humano.

ABSTRACT: This study aimed to reflect about the challenges of training teachers responsible for the literacy of children, especially from the conception of language writing as a cultural instrument complex, whose appropriation develops superior psychological functions. From a historic-cultural perspective of human development, it was realized how great these challenges are, given the fragmented nature of teacher education, which tend to take rhetoric as theory and activism as practice, disconnecting two aspects of human knowledge production. Moreover, it is a formation that has not sufficiently covered the contents to be taught to children, giving priority to the minimum capabilities that serve the everyday life at the expense of maximum capacities achieved by mankind. The written language and its teaching are objects that are complex, specific, not everyday, conceptual, which can be only truly understood by way of conceptual thought, which also needs to be taught. Thus, although the overcoming of functional illiteracy in the country seems far, we believe that the mediation of abstractions, in teacher training, is an essential way to fight for the right of all people to the development of reading and writing skills.

KEYWORDS: Teacher training. Appropriation of writter language. Human development.

\section{Introdução}

Se a linguagem é, segundo Marx, a consciência real, prática dos homens, constituindo-se, simultaneamente, como meio e produto da atividade social (MARX; ENGELS, 2002), lutar para que ela seja indistintamente desenvolvida entre as pessoas tem caráter revolucionário em um mundo marcado pela exacerbação das diferenças e das privações.

Partindo do pressuposto de que a apropriação da linguagem, em suas múltiplas manifestações, é direito inalienável do homem e instrumento essencial do desenvolvimento das capacidades especificamente humanas (VYGOTSKI, 2001, 2012) e que, no longo processo histórico pelo qual tem passado a humanidade, com base na atividade prática, os sujeitos têm constituído, em seu cotidiano, formas de expressar 
suas ideias, de comunicar-se e de constituir, solidária e contraditoriamente, suas consciências a respeito do mundo que os cerca, falar em luta pela apropriação da linguagem pode parecer um paradoxo. Entretanto, se considerarmos que a cotidianidade de homens, mulheres e crianças é caracterizada pelo acesso pauperizado à cultura historicamente acumulada, embora tenhamos consciência de que as pessoas se comunicam em todos os níveis e classes sociais e que vivem sua cotidianidade mediada pelas diferentes linguagens humanas, é importante que saibamos que o distanciamento entre a vida e os constructos da cultura, expressa principalmente na e pela escrita nas sociedades letradas, representa a imposição de um abismo entre as capacidades efetivamente desenvolvidas e aquelas passíveis de desenvolvimento pelo gênero humano.

Trata-se, pois, do fenômeno da alienação, que distancia cada sujeito das efetivas possibilidades de seu vir a ser; que perpetua a cisão entre o desenvolvimento humano universal e a vida de cada pessoa (HELLER, 2000). Pensar a apropriação da linguagem escrita, seus desafios e possibilidades implica refletir sobre essas questões de fundo. Como tem se consolidado, nas escolas, o processo multifacetado da alfabetização? (SOARES, 2004). Em que medida o trabalho pedagógico tem contribuído para a minimização da alienação das crianças brasileiras em relação à cultura do escrito que marca as sociedades letradas? Como a superação das obviedades que envolvem o trabalho docente pode colaborar para a formação de leitores e escritores, de forma que objetivos humanizadores se sobreponham aos objetivos traçados pelos órgãos multilaterais, cuja atenção se volve para os processos de alfabetização a partir de uma perspectiva produtivista e mercadológica? (MORTATTI, 2013).

Neste artigo, buscamos problematizar essas questões. Iniciamos refletindo sobre as relações entre a apropriação da escrita e o processo de desenvolvimento humano a partir da perspectiva histórico-cultural para, em um segundo momento, deter nossa atenção sobre a formação de professores alfabetizadores como formação conceitual necessária para a superação dos quadros de analfabetismo funcional que continuam a assolar nosso país. 


\section{Apropriação da linguagem escrita como possibilidade de humanização da criança}

A escrita é um sistema de signos construído e reconstruído no decorrer da história da humanidade, com o objetivo de registrar ideias, documentar fatos, expressar, comunicar e permitir a interação entre os membros do gênero humano que compartilham seus significados culturais e que, conhecendo o sistema pelo qual essa linguagem se organiza, podem atribuir sentidos ao que ela registra e representa (SMOLKA, 2012). Trata-se, segundo Mello (2011), de um instrumento cultural complexo, cujo processo de construção-uso-reconstrução desempenha um papel importante no desenvolvimento intelectual do ser humano e na formação de sua consciência.

É importante compreender que, com base no referencial histórico-cultural, é no complexo processo de apropriação (internalização ou assimilação da atividade humana incrustada nos objetos materiais e imateriais, que possibilita a inserção do indivíduo no gênero humano) e objetivação (produção ou transformação de objetos materiais e imateriais constituídos como portadores da atividade humana) (DUARTE, 1999), que ocorrem na atividade que o indivíduo desenvolve ao lidar com a natureza e com a cultura, que o ser humano desenvolve seu psiquismo, ou as denominadas funções psíquicas superiores (VYGOTSKI, 2012). Relembramos, assim, a máxima marxiana de que ao agir sobre a realidade, o homem a transforma na mesma proporção que transforma a si mesmo.

Nesse sentido, a apropriação da linguagem (e, especialmente, da escrita) representa a superação dos limites da experiência sensorial imediata e o acesso progressivo a níveis de pensamento abstrato, sob a forma de conceitos, o que permite ao sujeito penetrar mais profundamente na possibilidade de compreender a realidade pela mediação de abstrações, já que

[...] o processo de leitura transforma, enquanto constitui os modos de percepção da própria escrita; [...] a escrita, enquanto trabalho de explicitação e organização, também transforma e constitui o movimento discursivo interior. Desse modo, a escrita, como instrumental elaborado pelos homens, transforma, pela sua utilização, as estruturas psicossociais dos próprios homens. (SMOLKA, 2012, p.92). 
Isso significa dizer que, uma vez que o sujeito se apropria da linguagem escrita como um instrumento cultural complexo, como um sistema de signos que lhe permite se relacionar com o mundo, com as pessoas e consigo mesmo de maneira completamente nova, mediada, ele desenvolve uma nova função psíquica superior que lhe possibilita novas apropriações e objetivações. A linguagem escrita é, pois, simultaneamente, capacidade a ser formada na atividade do sujeito sobre o mundo e signo que potencializa novas apropriações, meio de assimilação do conhecimento humano nela acumulado. Aí reside a importância da educação escolar com relação à alfabetização das crianças: possibilitar-lhes o máximo desenvolvimento das capacidades discursivas, linguísticas, sócio e psicolinguísticas conquistadas pelo gênero humano e, com elas, de novas e mais complexas formas de pensar, de compreender e de participar da realidade concreta.

Nesse sentido, ao discutirmos o processo de apropriação da linguagem escrita pela criança, estamos nos referindo a um processo pelo qual ela precisa reconstruir para si esse objeto cultural, em situações semelhantes àquelas que motivaram o gênero humano a produzir a escrita, descobrindo suas características e seu funcionamento, sobremaneira, sua função social. Em outras palavras, é preciso que a criança se aproprie da linguagem escrita por meio de uma atividade específica, motivada por uma necessidade real, demandada pelas práticas sociais que envolvem essa linguagem e em cooperação com aqueles que já se apropriaram desse objeto cultural. Segundo Vygotski (2012, p.184), “[...] o domínio da linguagem escrita significa para a criança dominar um sistema de signos simbólicos extremamente complexo". E, para que isso aconteça, a escrita deve ser, sobretudo, um objeto com significado (é essencial que a criança conheça a sua função social e não meramente escolar) e sentido (LEONTIEV, 1978), ou seja, é preciso que a criança vivencie experiências em que a linguagem escrita seja, para ela, uma necessidade e um instrumento de sua expressão.

Considerando, ainda, que estamos falando de um tipo de objetivação nãocotidiana - objetivações mais complexas e elaboradas que não servem para satisfazer as necessidades imediatas de sobrevivência do homem, mas surgem à medida que esse amplia seu domínio sobre a natureza e sobre si mesmo (MELLO, 2000), a apropriação da linguagem escrita não é algo que ocorra de maneira empírica (apenas pela observação ou contato direto) como ocorre, por exemplo, com a fala, com os usos dos objetos e com os costumes de uma determinada sociedade: as objetivações em-si, próprias da cotidianidade (HELLER, 2000). Para que ocorra a apropriação das 
objetivações não-cotidianas, que exigem uma relação mais consciente com o conhecimento, faz-se necessária uma atitude intencional que requer perceber a linguagem escrita como objeto de reflexão, o que demanda o desenvolvimento do pensamento teórico (VYGOTSKI, 2001).

Isso significa dizer que o desenvolvimento das capacidades de ler e escrever requerem uma relação duplamente mediada entre a criança e a escrita. Em um primeiro plano, uma relação mediada pelos usos sociais que configuram a cultura escrita e a ela dão sentido. O segundo plano é mediado pela progressiva compreensão de que os significados verbais, ou as palavras, podem ser representados graficamente a partir de uma lógica própria, que envolve tanto as relações grafo-fonológicas que permitem a representação simbólica e sua compreensão quanto (e principalmente) as diversificadas possibilidades de dizer aquilo que se deseja a quem se deseja: as diferentes formas pelas quais o discurso escrito se constrói e intermedeia as relações (ideológicas, de poder, dialógicas) entre as pessoas (BAKHTIN, 1995). O pensamento conceitual ao qual a apropriação da linguagem escrita apresenta-se como fundamento representa a complexa capacidade de compreender a realidade com base em relações entre os significados das palavras, que evoluem e se generalizam à medida que se agrupam semanticamente, tornando-se passíveis da atribuição de sentidos (VYGOTSKI, 2001). Para Vygotski (2001, p.333, tradução nossa),

\begin{abstract}
A palavra está inserida em um contexto do qual toma seu conteúdo intelectual e afetivo, se impregna desse conteúdo e passa a significar mais ou menos o que significa isoladamente e fora do contexto: mais porque se amplia seu repertório de significados, adquirindo novas áreas de conteúdo; menos, porque o contexto em questão limita e concretiza seu significado abstrato. [...] O verdadeiro sentido de cada palavra está determinado, definitivamente, pela abundância de elementos existentes na consciência referidos àquilo que expressa a palavra em questão.
\end{abstract}

No entanto, apesar de a escrita referir-se a significados e sentidos historicamente constituídos, a história da alfabetização nos revela uma tradição inventada (MORTATTI, 2013) para a qual a palavra é fragmentada em duas partes isoladas: sons e significados, sem que a apropriação da linguagem escrita seja compreendida como um processo de formação de conceitos, no interior do qual as relações entre letras e sons são um aspecto, mas não o único e nem mesmo o mais importante. Ainda hoje, é possível encontrar professores que priorizam ou mesmo trabalham exclusivamente esse aspecto e 
acabam contribuindo para que a criança compreenda equivocadamente a escrita e sua função: um instrumento que serve somente às tarefas escolares (MELLO, 2011). A esse respeito, Vygotski (2012, p.183, tradução nossa) afirmou: “[...] à criança se ensina a traçar letras e a formar com elas palavras, porém não se ensina a linguagem escrita”. Smolka (2012) assevera que:

O problema, então, é que a alfabetização não implica, obviamente, apenas a aprendizagem da escrita de letras, palavras e orações. Nem tampouco envolve apenas uma relação da criança com a escrita. A alfabetização implica, desde a sua gênese, a constituição do sentido. Desse modo, implica, mais profundamente, uma forma de interação com o outro pelo trabalho de escritura - para quem eu escrevo, o que escrevo e por quê?(SMOLKA, 2012, p.95, grifos no original).

Gontijo (2008) explica que a produção de sentidos no momento da leitura e da escrita é uma condição sine qua non do processo de apropriação da linguagem escrita. À medida que a criança lê e escreve com a colaboração e intervenção do professor e de outros leitores - que podem ser, inclusive, crianças de maior idade ou experiência com a cultura escrita -, tem a oportunidade de pensar sobre esse objeto e cria a necessidade de conhecer suas características e funcionamento. Portanto, é lendo e escrevendo que a criança se apropria da linguagem escrita, descobrindo suas características externas e sua lógica interna. Porém, não é lendo e escrevendo qualquer coisa, de qualquer jeito que a criança se apropria do significado desse instrumento cultural. Segundo Mello (2011, p.7):

\begin{abstract}
Inserida em exercícios de leitura [assim como treinos envolvendo forma, nome e sons de letras] que não criam nas crianças motivos coincidentes com a função para a qual a leitura existe como objeto cultural, a criança não constitui a leitura [a produção de texto e a análise sobre o funcionamento da escrita] como atividade. Com isso, constrói para a leitura [linguagem escrita] um sentido que a distancia deste instrumento cultural essencial na apropriação da experiência humana acumulada - por sua, vez fonte do processo de humanização que cada um precisa viver na ontogênese para formar para si as qualidades humanas em suas máximas possibilidades.
\end{abstract}

Assim, é interessante observar como aquilo que é pensado pelos professores para estimular a leitura e a escrita (muitas vezes referindo-se apenas aos aspectos externos) acaba mais atrapalhando do que ajudando nesse processo, exatamente porque os aspectos externos da escrita não revelam a essência dessa linguagem. E a tarefa 
realizada mecanicamente pela criança não se configura como uma atividade que possa resultar na sua apropriação de modo a desenvolver uma nova função psicológica propriamente humana.

Dito de outro modo, apesar de todo esforço e boa vontade dos professores, o que temos presenciado são práticas escolares que mais prejudicam do que ajudam no processo de apropriação da linguagem escrita como um sistema de signos que carregam os significados presentes na sociedade e que permitem a interação entre as pessoas (GONTIJO, 2008).

Por outro lado, se o trabalho realizado na escola prioriza o aspecto funcional da linguagem escrita, sem desconsiderar os aspectos técnicos; se a criança se relaciona desde cedo com a escrita como um sistema de signos, buscando se apropriar desse objeto cultural complexo, a partir de atividades que aproximem o sentido que a criança atribui ao significado cultural da linguagem escrita, certamente, tal processo de apropriação, mais do que possibilitar à criança fazer parte de práticas sociais letradas, vai resultar em desenvolvimento de novas funções psíquicas superiores. Isso porque, como Vygotski (2001) assegura, a assimilação da linguagem escrita e, assim, das capacidades de ler e escrever, “[...] é uma das matérias mais importantes da instrução escolar no início da escolarização, já que favorece o desenvolvimento de todas as funções que ainda não tenham se formado na criança." (VYGOTSKI, 2001, p.242, tradução nossa). Entendemos, portanto, que ao ajudar a criança a se apropriar da linguagem escrita estamos potencializando seu desenvolvimento geral.

Portanto, trata-se de um processo que tem como objetivo promover o desenvolvimento integral da criança, do qual o ensino da linguagem escrita faz parte. Não se trata de apenas desenvolver a habilidade de transformar o escrito em fala e representar a fala pela escrita. Partindo do pressuposto que o bom ensino é aquele que se adianta ao desenvolvimento (VYGOTSKI, 2001), a atividade do professor que alfabetiza assume grande importância e responsabilidade, uma vez que a ele cabe intervir de maneira intencional e sistematizada no processo de apropriação da linguagem escrita da criança, promovendo experiências recheadas de significado histórico, cultural e social do uso dessa linguagem, comprometidas com a aprendizagem que possibilite o desenvolvimento daquele que aprende. O professor e a professora, também, devem se reconhecer como portadores da cultura, portadores do novo a ser aprendido, aqueles que já tendo se apropriado da linguagem escrita podem ajudar a criança nessa tarefa, já que, na perspectiva aqui defendida, “[...] toda função no 
desenvolvimento cultural da criança aparece em cena duas vezes, em dois planos; primeiro no plano social e depois no psicológico, a princípio entre os homens como categoria interpsíquica e logo no interior da criança como categoria intrapsíquica". (VYGOTSKI, 2012, p.150, tradução nossa).

Nesse processo, professores e professoras também aprendem e vão se constituindo em sua profissionalidade à medida que realizam a atividade de ensino. Mas, cabe perguntar: em que medida os alfabetizadores e alfabetizadoras se apropriam dos conhecimentos necessários para conduzir a atividade da criança? Eles são realmente "portadores do novo", ou seja, apropriaram-se da linguagem escrita como um sistema de signos a partir do qual se relacionam com os demais e com o mundo nas práticas sociais letradas? Que sentidos atribuem à linguagem escrita, à leitura e à produção de textos? Como se deu ou se dá o processo formativo que lhes constituiu como professores dos anos iniciais?

\section{A formação de professores que intervêm no processo de apropriação da linguagem escrita das crianças}

Neste texto, assumindo uma posição diferente daquela que tem marcado as políticas de formação de professores em nosso país, constituídas a partir da lógica neoliberal, não atribuímos nem à formação e muito menos aos professores a missão de solucionar todos os males da educação e do país (FREITAS, 2014). Ao contrário, entendemos que tanto a formação como o trabalho docente, inseridos no contexto da sociedade capitalista, são condicionados pela ideologia dominante, pelas condições materiais e pelas relações de poder que se estabelecem nessa sociedade (BISSOLI; BOTH, 2016).

Em coerência com os pressupostos que sustentam nossa argumentação, entendemos que a realidade social é um constructo histórico, portanto, passível de transformação. E, para tanto, o papel da educação é indispensável. Formar o professor e a professora de crianças cujo trabalho tenha o objetivo de contribuir para $\mathrm{o}$ desenvolvimento omnilateral das pessoas, que no contexto das sociedades letradas significa, também, se apropriar da linguagem escrita como instrumento cultural complexo, é, em última instância, contribuir para transformação da sociedade.

Sabemos que, no Brasil, e também internacionalmente, a formação docente tem se consolidado como um campo de disputas entre pontos de vista distintos a respeito do 
que significa educar e de quais as implicações dessa compreensão para a prática desenvolvida nas escolas. Formar professores significa, pois, assumir posições filosófico-ideológicas e, para nós, colocarmo-nos a serviço de uma lógica de transgressão ao neotecnicismo que tem se levantado como bandeira, contrária ao aprofundamento teórico-conceitual necessário à efetiva formação docente (BISSOLI; BOTH, 2016).

Para Martins (2010, p.14), a formação de qualquer profissional, inclusive do professor, deve ser entendida como “[...] uma trajetória de formação de indivíduos, intencionalmente planejada, para a efetivação de determinada prática social". Assim, ao pensarmos a formação de professores, precisamos ponderar sobre uma trajetória formativa que seja intencionalmente planejada para possibilitar aos indivíduos condições de efetivar sua prática social que envolve, dentre outros aspectos e principalmente, a atividade de ensinar. Para tanto, é preciso ter claro o motivo e o objetivo de ensinar (Por quê? Para quê?) e antecipar idealmente as ações que possibilitem efetivar tal ensino (planejar o 'o quê' e o 'como'). Segundo SánchezVázquez (2011, p.265, grifo nosso):

[...] o fim não pode deixar de dominar - isto é, a consciência não pode bater em retirada no processo prático -, e por isso tem de estar alerta às exigências imprevistas do processo objetivo de realização, isto é, a consciência não pode limitar-se a traçar um fim ou modelo ideal imutável. [...] O resultado real só é alcançado ao cabo de um processo prático, objetivo, que ultrapassa a cada momento o resultado ideal. Por conseguinte, a consciência tem de permanecer ativa ao longo de todo esse processo, não só buscando impor o fim original, mas também modificando-o em prol da sua realização.

Ao fazer uma análise sobre o legado do século XX para a formação de professores, Martins (2010) tece uma série de considerações sobre a influência de agências internacionais nas políticas educacionais em nosso país, incluindo aí a formação de professores. Mas, dentre as questões que a autora apresenta, chama-nos atenção o destaque dado ao que ela denomina de esvaziamento da formação docente, uma vez que as políticas de formação empreendidas nos últimos vinte anos, seguindo recomendações do Banco Mundial, têm desprezado a teoria em favor da prática, na verdade, do aspecto técnico da prática, que passa a ser separada de seus fundamentos teóricos e apoiada no cotidiano, na experiência ou mesmo em especulações do que seja a realidade escolar. 
As conclusões de Martins (2010) sobre a valorização do aspecto técnico da prática em detrimento da teoria fazem-nos pensar na metáfora da curvatura da vara (SAVIANI, 2008) já tão discutida em educação. Na tentativa de superar o problema da dicotomia teoria e prática resultante do enfoque nos conteúdos científicos da formação, apresentados em dissociação com a prática a partir do entendimento de que essa seria, simplesmente, a aplicação dos conceitos supostamente apreendidos, com base no que os cursos de formação de professores eram acusados de ser excessivamente teóricos (PIMENTA, 2006; SILVA, 2011), começam a surgir propostas de valorização da prática "entortando a vara" para o outro lado, o que não se configurou ainda como um caminho adequado à formação de professores, tendo em vista que,

[...] para que os professores e professoras em formação compreendam as especificidades do trabalho educativo, não basta a memorização de um conjunto de ideias com importância em si mesmas, divorciadas entre si e do conhecimento daquilo que acontece nas escolas. Isso não é teoria; é retórica. Também não é suficiente a mera aplicação de técnicas e prescrições curriculares sem o conhecimento efetivo de seus objetivos e possibilidades de intervenção em uma realidade complexa, sem reflexão crítica. Isso não é prática; é ativismo. (BISSOLI; BOTH, 2016, p.25).

Parece-nos que a formação, ainda hoje, não oferece elementos que ajudem a superar o ditado "na prática, a teoria é outra". Sendo assim, entendemos que as palavras de Pimenta (2006, p.52) se mostram ainda muito atuais:

\footnotetext{
"Na prática a teoria é outra". No cerne dessa afirmação popular aplicada à formação de professores está a constatação de que o curso nem fundamenta teoricamente a atuação da futura professora [ou do futuro professor], nem toma a prática como referência para a fundamentação teórica. Ou seja, carece de teoria e de prática.
}

Portanto, o esvaziamento apontado por Martins (2010) e outros educadores não é uma novidade na formação de professores no Brasil. A relação entre teoria e prática tem se mostrado um grande problema nessa formação e, consequentemente, na atividade de ensino desempenhada nas escolas. Desconsidera-se que a prática, critério de verdade, finalidade e motivo da teoria, não significa um conjunto de ações que pretensamente se tornam teóricas com o passar do tempo. Segundo Vygotski (2001), o pensamento espontâneo, aquele que se constrói na ação real e efetiva sobre o mundo, embora necessária base para a construção de conceitos, não é, ainda, pensamento conceitual. 
Nesse sentido, discutir a prática sem o aporte de elementos conceituais que permitam vislumbrá-la sob novas luzes não desenvolve formas mais complexas de compreensão da realidade. Kosik (2002) denomina as concepções produzidas pelo pensamento espontâneo de representações acerca do real, que não ultrapassam o limite da pseudoconcreticidade.

Ora, se a compreensão efetiva da realidade e de seus múltiplos determinantes não é acessível às consciências apenas pela observação dos fenômenos, pela ação e pelo pensar cotidiano a respeito de suas resultantes, ela implica, também, o conhecimento de suas causas. E isso apenas é possível pela mediação de um conhecimento mais elevado, científico-filosófico-artístico a respeito do real. É preciso ultrapassar a aparência em direção à essência e isso ocorre quando, às pessoas, é possibilitada a apreensão de conhecimentos não-cotidianos. Nesse sentido, a apreensão da realidade como totalidade concreta é resultado da formação de um pensamento mais elevado, consciente e intencional: o pensamento conceitual.

Ao pensar a questão da relação teoria e prática na formação de professores, encontramos, no trabalho de Silva (2011), elementos para pensar essa relação na contemporaneidade, a partir das concepções de formação surgidas a partir de 1990. Em uma análise dos trabalhos realizados sobre o estado da arte referentes à formação docente, essa autora nos mostra que, no mesmo período em que são feitas as amplas reformas educacionais no país, intensificam-se as pesquisas sobre a formação de professores em uma perspectiva que:

[...] de modo geral, parece estar associada: à noção de professor como sujeito, produtor de conhecimentos e responsável pelo seu processo formativo; à noção de pesquisa como instrumento fundamental tanto na formação como na prática do professor; à prática concebida como lócus de formação e produção de conhecimento, bem como à valorização desse conhecimento que advém da prática educativa do professor. (SILVA, 2011, p.13).

Tais ideias se intensificam no Brasil influenciadas pelas publicações de Os professores e sua formação do autor português Nóvoa (1992) e Cartografia do trabalho docente dos autores brasileiros Geraldi, Fiorentini e Pereira (1998). A publicação dessas obras possibilitou a fundamentação e sistematização das discussões já iniciadas no Brasil desde o final dos anos de 1980 e, que em linhas gerais, faziam críticas ao tecnicismo e apontavam a necessidade de valorizar a prática, o cotidiano 
escolar, a pesquisa e os conhecimentos da experiência docente na formação de professores, valorizando o protagonismo do professor (SILVA, 2011).

Nas reflexões sobre como têm se configurado os cursos de formação de professores a partir do final do século XX e início desse século, chama-nos a atenção a preocupação com as supostas soluções para a formação docente, uma vez que as pesquisas têm mostrado uma fragilidade na formação de professores com ênfase na prática (aspecto técnico). Para além de todos os problemas já apontados pelos autores aqui citados, precisamos questionar: como sustentar uma formação que tem a prática como ponto de partida e de chegada, em um contexto de mudanças do perfil do alunado dos cursos de pedagogia, que hoje, em sua maioria não têm nenhuma experiência em docência? Ao "curvar a vara" para a prática que inexiste (na maioria dos casos) podemos estar incorrendo num erro ainda mais grave, quando supostamente havia um excessivo enfoque na teoria (confundida com retórica). Ou ainda, presenciar aquilo que Pimenta (2006) já afirmava há mais de vinte anos: a persistência de uma formação que carece tanto de teoria como de prática.

Para Libâneo (2013), ao pensar a formação específica dos professores dos anos iniciais, que são os responsáveis pelo processo de apropriação da linguagem escrita (dentre tantas outras coisas):

[...] um curso de licenciatura para professores dos anos iniciais do ensino fundamental necessita prover o domínio dos saberes disciplinares a serem ensinados; a apropriação de metodologias, procedimentos e modos de ação, em função do trabalho na escola; e uma visão dos contextos em que se dá o ensino, para assegurar sua qualidade. (LIBÂNEO, 2013, p.77).

No entanto, analisando trabalhos recentes sobre cursos de pedagogia no Brasil, o autor conclui que o caráter teórico ainda é predominante e que as práticas a ele associadas são pouco contempladas. Questionamos: de que teoria se trata, quando esta não está associada à prática? Os cursos teriam, realmente, um predomínio teórico?

Gatti e Nunes (2009), além de identificarem, nos cursos, um predomínio das disciplinas tidas como teóricas, consideram insuficiente (quase que inexistente) a presença dos conteúdos das disciplinas que os professores precisam ensinar às crianças. Fato extremamente preocupante se pensarmos que na sala de aula, o professor deveria ser o portador do novo para a criança. Em termos de conteúdos escolares, ele deveria ser 
aquele que, já conhecendo os conteúdos, pensa a forma como as crianças vão fazer suas próprias apropriações.

Em relação ao conteúdo e aos métodos específicos do processo de apropriação da linguagem escrita que precisam ser tomados como objetos de apropriação nos cursos de formação de professores, Chartier (1998, p.4) nos chama a atenção para o caráter histórico-cultural na definição dos mesmos, asseverando: “[...] o conteúdo e os métodos de ensino mudam à medida que a demanda social de alfabetização se transforma e, assim, as competências que se esperam dos professores não cessam de ser redefinidas". No Brasil, Mortatti (2008) é uma das pesquisadoras que tem se dedicado a estudar a história da alfabetização e seus trabalhos corroboram a afirmação de Chartier (1998), mostrando, por meio da questão da "querela dos métodos", a não superação de uma visão estritamente técnica do que seria a alfabetização.

No tocante à formação dos professores que alfabetizam, Mortatti (2008) destaca o fato de a história da alfabetização no Brasil mostrar a consolidação de um modelo de formação no qual o essencial é ensinar o professor a aplicar as "novas" propostas criadas para responder as urgências políticas e sociais de cada momento histórico, e que coloca os cursos de formação de professores a serviço de programas oficiais de ensino. Segundo a autora,

\footnotetext{
Desse ponto de vista resulta e se dissemina uma concepção reducionista, segundo a qual "bom" professor é, geralmente, aquele que sabe aplicar/executar as propostas oficiais de maneira eficiente e eficaz e de acordo com os objetivos formulados pelos sujeitos que conceberam essas propostas e que são, também, os avaliadores (externos) da prática docente, de maneira direta ou indireta (por meio de estatísticas de avaliações gerais, dados sobre reprovação, evasão de alunos, por exemplo). (MORTATTI, 2008, p.474).
}

Entendida desse modo, a formação do professor que alfabetiza “[...] foi-se tornando, gradativamente, 'profissionalizante', perdendo seu caráter de formação com base em estudos tanto de cultura geral quanto de fundamentação teórica específica" (MORTATTI, 2008, p.475) e pouco tem a ver com um trabalho intelectual, separando as atividades especificamente humanas de conceber, executar e avaliar no sujeito que ensina.

Mortatti (2013, p.29), também, vai alertar que, em tempos de "aprender a aprender" (slogan que sintetiza a lógica neoliberal na educação), tanto a formação inicial como a continuada dos professores dos anos iniciais do ensino fundamental é 
entendida "[...] como processo de aprender (por convencimento, não por entendimento) a aplicar e a treinar" (MORTATTI, 2013, p.29), uma vez que o professor é visto “[...] como executor (convencido, mas não convincente) de políticas públicas e metas globais para a alfabetização escolar".

Nesse sentido, a discussão sobre a formação do professor que alfabetiza, aqui empreendida, revela-nos uma formação que ainda não conseguiu resolver o problema da relação teoria e prática. Vemos que teoria se confunde com retórica e prática com ativismo: uma retórica sobre a escola ideal que nada diz aqueles que realizam sua prática em uma escola real e, uma prática individual baseada no senso comum já que não busca fundamentos na produção do conhecimento acumulado socialmente. Uma formação que desvincula o como ensinar do seu conteúdo de ensino e, com isso, pouco contribui para que o professor se aproprie dos conteúdos necessários à sua atividade de ensino.

No que diz respeito à apropriação da linguagem escrita, antes de ensinar métodos ou propostas para ensinar a ler e escrever às crianças, é necessário que a formação possibilite ao professor que está sendo formado situações em que ele próprio se aproprie do conteúdo da alfabetização, que intencionalmente tome consciência das características e funcionamento interno desse objeto a ser apropriado e objetivado. É preciso que, no processo de formação, o próprio professor se relacione com a linguagem escrita como objeto cultural complexo, vivenciando situações que aproximem os sentidos, atribuídos por ele ao ler e escrever, e o significado cultural da escrita. Nas palavras de Mello (2011, p.13), a formação deve ajudar o professor a "[...] compreender o processo de apropriação da cultura escrita em novas bases: sob o olhar da ciência, a partir das muitas pesquisas que se tem realizado sobre a apropriação da cultura escrita na perspectiva de formação de crianças leitoras e produtoras de texto". Acreditamos que, partindo dessas ideias, possamos admitir que o professor seja considerado o portador de cultura que ajudará a intervir de maneira significativa na apropriação da linguagem escrita das crianças.

\section{Considerações finais}

Pensar a formação de professores e professoras alfabetizadoras, na perspectiva de que a apropriação da linguagem escrita represente uma nova qualidade de 
pensamento, de vida e de participação para todas as crianças, implica, como temos destacado ao longo deste artigo, rever e ressignificar as relações entre teoria e prática. Formar professores e professoras que contribuam para que a linguagem escrita seja uma capacidade efetiva significa, pois, prover espaços, tempos, relações e oportunidades para que eles mesmos, adultos, desenvolvam-se como efetivos leitores e escritores.

O desenvolvimento do pensamento conceitual, que capacita professores e professoras para um trabalho intencional, sistemático e objetivo sobre as capacidades em desenvolvimento nas crianças, exige um movimento de aproximação entre esses sujeitos e os constructos das Ciências, das Artes, da Filosofia. É a sua apropriação o elemento-chave do desenvolvimento das consciências, em uma perspectiva dialógica.

Em se tratando especificamente da leitura e da escrita, é preciso que professores e professoras em formação tenham acesso a textos variados, à cultura geral ampla e aos conhecimentos específicos a respeito do que caracteriza o desenvolvimento das capacidades de ler e de escrever para além da técnica e rumo à produção de significados e sentidos.

Se a linguagem escrita é instrumento de desenvolvimento humano omnilateral e possibilidade de humanização, cabe aos cursos de formação uma atenção especial à ampliação de referências de seus estudantes. Cabe admiti-los na cultura escrita como sujeitos capazes de aprender (e de transformar) a realidade por seu intermédio.

\section{REFERÊNCIAS}

BAKHTIN, M. Marxismo e filosofia da linguagem. São Paulo: Hucitec, 1995.

BISSOLI, M. F.; BOTH, I. I. Dos sentidos da formação aos sentidos do trabalho docente. In: CORREAA, C. H. A.; CAVALCANTE, L. I. P.; BISSOLI, M. F. (Org.). Formação de professores em perspectiva. Manaus: EDUA, 2016. p.15-55.

CHARTIER, A. M. Alfabetização e formação dos professores da escola primária. Revista Brasileira de Educação, Rio de Janeiro, n.8, p.4-12, mai./ago. 1998.

DUARTE, N. A individualidade para-si: contribuição a uma teoria histórico-social da formação do indivíduo. Campinas: Autores Associados, 1999.

FREITAS, L. C. Os reformadores empresariais da educação e a disputa pelo controle do processo pedagógico na escola. Educação \& Sociedade, Campinas, v.35, p.1085-1114, 2014. 
GATTI, B. A.; NUNES, M. M. R. (Org.). Formação de professores para o ensino fundamental: estudo de currículos das licenciaturas em pedagogia, língua portuguesa, matemática e ciências biológicas. São Paulo: FCC/DPE, 2009.

GERALDI, C. M. G.; FIORENTINI, D.; PEREIRA, E. M. A. (Org.). Cartografias do trabalho docente: professor(a)-pesquisador(a). 1.ed. Campinas: Mercado de Letras, 1998.

GONTIJO, C. M. M. A escrita infantil. São Paulo: Cortez, 2008.

HELLER, A. Cotidiano e história. Rio de Janeiro: Paz e Terra, 2000.

KOSIK, K. Dialética da totalidade concreta. In: KOSIK, K. Dialética do concreto. Rio de Janeiro: Paz e Terra, 2002. p.13-64.

LEONTIEV, A. N. Actividade, consciencia y personalidad. Buenos Aires: Ciencias Del Hombre, 1978.

LIBÂNEO, J. C. Licenciatura em pedagogia: a ausência dos conteúdos específicos do ensino fundamental. In: GATTI, B. A. et al. (Org.). Por uma política nacional de formação de professores. São Paulo: Ed. da Unesp, 2013. p.73-94.

MARTINS, L. M. O legado do século XX para a formação de professores. In: MARTINS, L. M.; DUARTE, N. (Org.). Formação de professores: limites contemporâneos e alternativas necessárias. São Paulo: Cultura Acadêmica, 2010. p.1331 .

MARX, K.; ENGELS, F. A ideologia alemã. São Paulo: Centauro, 2002.

MELLO, S. A. Linguagem, consciência e alienação: o óbvio como obstáculo ao desenvolvimento da consciência crítica. Marília: Unesp Marília Publicações, 2000.

MARX, K.; ENGELS, F. Produção de sentidos e formação de leitores. In: V ENCONTRO BRASILEIRO DE EDUCAÇÃO E MARXISMO: Marxismo, Educação e emancipação humana, Florianópolis, 2011. Anais... Florianópolis: UFSC, 2011. p.1-14.

MORTATTI, M. R. L. Notas para uma história da formação do alfabetizador no Brasil. Revista brasileira de estudos pedagógicos, Brasília, v.89, n.223, p.467-476, set./dez. 2008.

MORTATTI, M. R. L. Um balanço crítico da "década da alfabetização" no Brasil. Caderno Cedes, Campinas, v.33, n.89, p.15-34, jan./abr. 2013.

NÓVOA, A. (Org). Os professores e a sua formação. Lisboa: Publicações Dom Quixote, 1992.

PIMENTA, S. G. O estágio na formação de professores: unidade entre teoria e prática? 7.ed. São Paulo: Cortez, 2006.

SÁNCHEZ VÁZQUEZ, A. Unidade da teoria e da prática. In: SÁNCHEZ VÁZQUEZ, A. Filosofia da práxis. São Paul: CLACSO, 2011. p.241-266. 
SAVIANI, D. Escola e democracia: teorias da educação, curvatura da vara, onze teses sobre a educação política. 40.ed. Campinas: Autores Associados, 2008.

SILVA, L. N. D. Formação de professores centrada na pesquisa: a relação teoria e prática. 2011. 163 f. Tese (Doutorado em Educação) - Faculdade de Educação, Universidade Federal de Goiás, Goiânia, 2011.

SMOLKA, A. L. B. A criança na fase inicial da escrita: a alfabetização como processo discursivo. 13.ed. São Paulo: Cortez, 2012.

SOARES, M. Letramento e alfabetização: as muitas facetas. Revista Brasileira de Educação, Rio de Janeiro, n.25, p.5-17, jan./abr. 2004.

VYGOTSKI, L. S. Obras escogidas II. Madrid: Machado Libros, 2001.

VYGOTSKI, L. S. Obras escogidas III. Madrid: Machado Libros, 2012.

\section{Como referenciar este artigo}

ROCHA, Sônia Cláudia Barroso da; BISSOLI, Michelle de Freitas. Desafios da formação de professores alfabetizadores: em busca da apropriação da linguagem escrita como desenvolvimento humano. Revista Ibero-Americana de Estudos em Educação, Araraquara, v.11, n. esp. 4, p. 2499-2516, 2016. Disponível em: <http://dx.doi.org/10.21723/riaee.v11.n.esp4.9206>. E-ISSN: 1982-5587.

Submetido em: agosto/2016

Aprovado em: outubro/2016 